\title{
Efeito econômico-financeiro das ações de prevenção das doenças na saúde das populações: uma revisão de literatura - primeiras notas
}

\author{
Neuza Ferreira do AMAZONAS(1) \\ Leonardo CARNUT $^{(1)}$
}

${ }^{(1)}$ Faculdade de Saúde Pública, Universidade de São Paulo - USP, São Paulo, SP, Brasil.

\section{Resumo}

Considerando-se que, quando se pensa em atenção à saúde, as principais ações e serviços não se restringem às atividades curativas propriamente ditas e deve-se ressaltar a importância constitutiva das ações de prevenção na complexidade que atenção no Sistema Único de Saúde - SUS compreende. Ao se pensar nas ações de prevenção como uma tecnologia, a Avaliação Tecnológica em Saúde - ATS também podem ser utilizadas como uma nova tecnologia que pode levar à redução dos custos em saúde quando se trata do orçamento do Ministério da Saúde. A ATS permite a escolha da tecnologia mais conveniente e atraente para a produção de saúde que ofereça segurança, eficácia e economicidade em relação às tradicionais. A ATS congrega as multidisciplinaridades objetivando a viabilização para aferição de resultados relacionados à segurança e a eficácia da tecnologia disponível, bem como a atuação destes profissionais na realização de novos estudos em casos de necessidade de evidenciar o desempenho de um

Recebido: 28 jan 2019 Aceito: 10 fev 2019

Autor de correspondência: neuza.famazonas@gmail.com

Conflito de interesses: Os autores declaram não haver nenhum interesse profissional ou pessoal que possa gerar conflito de interesses em relação a este manuscrito. determinado tratamento. As pessoas nascem com um estoque de saúde e nem sempre ótimo, que vai se depreciando ao longo do tempo com a idade em uma taxa crescente e que varia através do investimento. A taxa de depreciação da saúde é endógena, ou seja, dependente de cada um. A saúde pode ser tratada tanto como um bem de consumo como um bem de investimento. Como um bem de consumo, a saúde faz com que as pessoas se sintam melhor. Já como um bem de investimento a saúde é desejada porque aumenta o tempo saudável disponível para trabalhar e gerar renda. A saúde expressa qualidade de vida e é um produto social. A sociedade poderá acumular saúde ou desacumular saúde produzindo enfermidade social, implicando a necessidade de um novo modelo de atenção à saúde que considere-a como um investimento. Assim, o modelo de vigilância à saúde com operação intersetorial tem como pressuposto a articulação de diferentes estratégias de intervenção em especial aquelas relacionadas à prevenção de doenças. A organização do modelo de vigilância à saúde em sua prática é operacionalizada pela vigilância em saúde constituída pela articulação essencial entre vigilância epidemiológica, sanitária, ambiente e do trabalhador. Isso significa que, ao caracterizar as ações de prevenção, é necessário considerar todas ações da vigilância em saúde, caso queiramos dar a precisão analítica necessária aos efeitos econômico-financeiros que ocorrem em função do exercício destas ações. Assim, certamente, os custos e o efeito econômico esperado com a operacionalização destas ações preventivas, tidas 
muitas vezes como tecnologias leves podem justificar melhor o investimento necessário nesta área, justificando a saúde com um bem de investimento. Assim, pode-se dizer que há escasso debate sobre as evidências que existem sobre a relação entre o efeito econômico-financeiro das ações de prevenção e as doenças na saúde das populações. Objetivo: revisar a literatura científica sobre o efeito econômico-financeiro das ações de prevenção das doenças na saúde das populações. Como objetivos específicos, este estudo visa: (a) coletar os estudos que têm como objeto a relação efeito econômico-financeiro das ações e prevenção das doenças e a melhoria da saúde das populações, (b) classificar os estudos segundo o tipo de análise de tecnologias que é realizada e quais os níveis de efeito no investimento segundo os grupos de ações de prevenção que são estudadas e (c) analisar criticamente os resultados apresentados em função das incorporações no âmbito de ações no SUS. Método: o estudo trata-se de uma revisão narrativa, buscando bibliografias que tratam sobre a atenção à saúde do ponto vista relacionado ao efeito econômico-financeiro decorrentes das ações de prevenção das doenças nas pessoas, na perspectiva de obtenção de dados que apresentem evidências a serem utilizadas como suporte para esta pesquisa. O desenvolvimento para esta revisão teve como base inicial a identificação de bibliografias correlacionadas aos descritores do estudo a ser desenvolvido, através de busca por meio eletrônico na base de dados disponíveis no acervo da Biblioteca Virtual da Saúde - BVS. A busca e a seleção das bibliografias foram realizadas com a inserção das palavras do descritor da pesquisa para identificar artigos cujos descritores tenham relação. A partir do resultado encontrado, os descritores foram divididos em dois itens-chaves, sendo um diretamente ligado às questões econômicas e outro voltado à atenção à saúde. A composição sintática foi realizada com base nos itens chaves, identificados na pergunta da pesquisa e dividida em três polos: Investimento em saúde, 'Prevenção de doenças, Gastos em saúde. Para cada um, foram buscados descritores no Descritores em Ciências da Saúde - DeCS (http://desc.bvs.br/descritores), observadas as definições utilizadas na busca inicial. Para obtenção de abrangência nas buscas, foi utilizada a técnica do funil com a busca avançada pesquisando diversos cruzamentos. Considerações finais: a partir da técnica do funil realizada, foram selecionados os cruzamentos que apresentaram resultados mais expressivos na tentativa de responder a pergunta de pesquisa. A sintaxe final escolhida que mais se adequa pergunta de pesquisa foi: (mh:((mh:("Investimentos em Saúde")) $O R$ (mh:("/prevenção \& controle" )) $O R$ (mh:("prevenção primária")) OR (mh:("gastos em saúde")) )) AND (mh:("SUS")). Chegou-se a 327 resultados, dentre estes, 319 estavam no idioma português. Após análise dos artigos que apareceram nas buscas foram selecionados 13 artigos para realização de leitura na íntegra para análise reflexiva. Os demais resultados encontrados foram excluídos por não apresentarem relação direta com a pesquisa proposta.

Descritores: Investimentos em Saúde; Prevenção de Doenças; Gastos em Saúde. 